\title{
Evaluation of Betulinic Acid Effects on Pain, Anxiety, Catalepsy, and Oxidative Stress in Animal Model of Parkinson's Disease.
}

\section{Maryam Abrishamdar}

Ahvaz Jondishapour University of Medical Sciences

\section{Yaghoob Farbood ( $\sim$ farbood_y@yahoo.com)}

AJUMS: Ahvaz Jondishapour University of Medical Sciences https://orcid.org/0000-0002-6390-0079

\section{Alireza Sarkaki}

Ahvaz Jondishapour University of Medical Sciences

Mohammad Rashno

Ahvaz Jondishapour University of Medical Sciences

Mohammad Badavi

Ahvaz Jondishapour University of Medical Sciences

\section{Research Article}

Keywords: Parkinson, Betulinic acid, EPM, Shuttle box, SOD, BDNF

Posted Date: November 17th, 2021

DOI: https://doi.org/10.21203/rs.3.rs-1036837/v1

License: (c) (1) This work is licensed under a Creative Commons Attribution 4.0 International License. Read Full License 


\section{Abstract}

\section{Background}

Parkinson's disease (PD) is known by motor impairments. Betulinic acid (BA) is a natural active compound with potent antioxidant activity. The present study addresses the question whether BA affects motor dysfunctions, pain, anxiety and molecular changes in the rat model of PD.

\section{Methods}

Right medial forebrain bundle (MFB) was lesioned by injection of 6-OHDA in Male Wistar rats. BA (0.5, 5 \& $10 \mathrm{mg} / \mathrm{kg}$ ) and L-dopa (20 mg/kg) were administrated for 7 days. rigidity, anxiety, analgesia and memory, were assessed by bar test, open-field, elevated plus-maze (EPM), tail-flick and shuttle box. Additionally, the malondialdehyde (MDA), Superoxide dismutase (SOD), glutathione peroxidase (GPx) activity as well as Brain-derived neurotrophic factor (BDNF) and Interleukin 10 (IL10) levels in the brain tissue were measured.

Results

Treatment with BA significantly reversed the 6-OHDA-induced motor complication in the bar test, but it modified anxiety like behavior neither in open-field nor in EPM, it only decreased the time spent in open arms. Moreover no significant changes were found in the tail-flick between treatment and sham groups. On the other hand, the level of MDA \& IL10 were decreased, and the activity of GPx, levels of SOD \& BDNF in the rats brains were increased.

\section{Conclusion}

Our results showed that BA could affect as a potent natural free radical scavenger which removes brain tissue oxidants in PD. It can account a possible promise as a good therapeutic agent for motor and nonmotor complications in PD.

\section{Introduction}

Parkinson's disease (PD) is a slowly progressive neurodegenerative disease caused by degeneration of the dopaminergic neurons in the substantia nigra pars compacta (SNc) of the midbrain region leading to presence of Lewy bodies in the surviving dopamine neurons (Kesh, Kannan et al. 2021). It is mainly characterized by motor signs such as bradykinesia, resting tremor, rigidity and postural instability (Domenici, Campos et al. 2019). Besides originally described as a motor disease, Parkinson's disease (PD) patients suffer from a variety of non-motor symptoms such as sleep disorders, olfactory dysfunctions, anxiety, depression and pain (Faivre, Joshi et al. 2019). All these symptoms have a significant impact on their quality of life (Aarsland and Kramberger 2015), and usually appear a long time before the first motor signals (do Nascimento, Ferrari et al. 2020). Research on the pathogenesis of the 
PD has been mainly based on the development of animal models that reproduce the loss of dopaminergic neurons in the substantia nigra (Real, Garcia et al. 2017).

One commonly used model of PD involves unilateral lesion of dopaminergic pathways in rodents with the neurotoxin 6-hydroxydopamine (6-OHDA) (Lau, Patki et al. 2011). 6-OHDA is one of the most viable models to replicate the pathogenesis associated with $\mathrm{PD}$, since hydroxydopamine is observed in the blood and urine of PD patients (Kesh, Kannan et al. 2021). 6-OHDA was the first neurotoxin employed to cause damage specifically in neurons (Ungerstedt 1968) and the most used toxin in experimental PD models (Blandini, Armentero et al. 2008). In this procedure, 6-OHDA selectively destroys catecholaminergic neurons, and has the unique advantage of side-based motor impairment such as apomorphine circling and spontaneous motor activity that corresponds with loss of dopaminergic neurons (Schober 2004).

Many studies reveal that oxidative stress plays a vital role in the progression of PD, leading to cell death (Kesh, Kannan et al. 2021). The pathogenesis of PD centers on the formation of reactive oxygen species (ROS) and the onset of oxidative stress leading to oxidative damage to substantia nigra pars compacta (Betarbet, Sherer et al. 2000). Exposure to 6-OHDA mimics the PD effects like dopaminergic neurons death and increased ROS production (Gonçalves, Courtes et al. 2019). These toxic effects are attributed to the formation of various oxidants and free radicals, lipid peroxidation, depletion of the glutathione system, which is responsible for removing free radicals, and mitochondrial deficits (Teixeira, Souza et al. 2013).

Although the cause of PD remains unclear, evidence from many studies suggests the role of excitotoxicity and neuroinflammation as a key point in neural death (Goes, Jesse et al. 2018)There is a considerable interest in studying the involvement of neurotrophic factors that are substances known to be vital for survival of specific neurochemical phenotype of classes of neurons. Accumulated evidences suggest that microglial activation and insufficient support of neurotrophic factors may be crucial for the initiation and progression of this pathology (Staudt, Di Sebastiano et al. 2016).

Betulinic acid (BA), a pentacyclic triterpene derived from white birch trees, which is largely grows in south Asia (Yogeeswari and Sriram 2005), has recently been described as a useful antioxidant for preventing oxidative stress-related mitochondrial dysfunction, and as such may find use in the management of a range of acute and chronic disease processes (Souza, Rodrigues et al. 2011). BA has found its therapeutic use both in the ancient Indian form of medicine called "Ayurveda" for the treatment of central nervous system (CNS) disorders (Bhattacharya, Bhattacharya et al. 2000). Most importantly, BA is able to cross the blood-brain barrier, which makes it a compound suitable for the treatment of CNS disorders (Planchard, Samel et al. 2012).

Therefore, in this experiment, we examined the effect of BA on motor dysfunction, anxiety and pain in 6OHDA-induced rats three weeks after PD induction to demonstrate the potential protective effect of it for future therapeutic applications in PD. Also we investigated whether BA would counteract the metabolic disruption and the resulting behavioral deficits produced by the 6-OHDA model of PD in rats. 


\section{Material \& Methods \\ 2.1. Drugs and animals}

6-hydroxidopamine (6-OHDA), desipramine, apomorphine, betulinic acid (BA) and Levodopa/Carbidopa were purchased from Sigma-Aldrich Chemical Co. (St. Louis, MO, USA). Dimethyl sulfoxide (DMSO), Ketamine/Xylazine were obtained from Alfasan Co. (Woerden, Holland).

Forty-eight adult male Wistar rats (270-320 g) obtained from Ahvaz Jundishapur University of Medical Sciences (AJUMS) central animal Lab (Ahvaz, Iran). Rats were kept in the same room under a 12:12-hr light-dark cycle with food pellets and water, ad libitum. All experiments were carried out during the light phase of the cycle (08:00 am to 06:00 pm).

\subsection{Experimental design}

The animals were divided randomly into six groups of 7-8 in each:

1) sham operated (Sham-PD), received $4 \mu$ normal saline containing $0.01 \%$ ascorbic acid into right medial forebrain bundle (MFB)

2) lesioned (PD)+veh, received $20 \mu \mathrm{g} / 4 \mu \mathrm{l}$ 6hydroxydopamine dissolved in normal saline with $0.01 \%$ ascorbic acid into right MFB

3,4,5,) PD-BA, MFB-lesioned rats which received BA $(0.5,5$ and $10 \mathrm{mg} / \mathrm{kg}$, respectively, i.p.) dissolved in DMSO for 7 days

6) PD-L-dopa received (levodopa/carbidopa, $20 \mathrm{mg} / \mathrm{kg}$, p.o.) for 7 days was administered until 14 days after stereotaxic surgery (Uzar, Alp et al. 2012).

\subsection{Surgical Procedures}

Rats were given a 30 min-pretreatment of $25 \mathrm{mg} / \mathrm{kg}$ of desipramine dissolved in normal saline to reduce uptake of the 6-OHDA into adrenergic neurons and prevent their damage (Fine, Stroebel et al. 2020). Then they were anesthetized (ketamine $70 \mathrm{mg} / \mathrm{kg}+$ xylazine $4 \mathrm{mg} / \mathrm{kg}$, i.p.) (Razavinasab, Shamsizadeh et al. 2013). and placed in a stereotaxic apparatus (Narishige, Japan) and fitted. The nigrostriatal dopaminergic pathway that is implicated in PD consists of dopaminergic neurons located in the SNc that extend axons along the median forebrain bundle (MFB) and terminate in the dorsal striatum (De JesúsCortés, Miller et al. 2015).

A midline incision was made from the mid-orbital region to the occipital ridge. A hole was drilled through the skull at AP: $-4.4 \mathrm{~mm}, \mathrm{ML}:+1.3 \mathrm{~mm}$ from bregma and DV: $-8.4 \mathrm{~mm}$ from skull surface (on the right side). To make PD model, a $10 \mu \mathrm{L}$ Hamilton syringe was filled with freshly prepared 6-OHDA $(20 \mu \mathrm{g} / 4 \mu \mathrm{l}$ normal saline containing $0.01 \%$ ascorbic acid) or its vehicle (in sham groups) and lowered (from dura 
mater) into the right MFB. The coordinates were chosen to target the MFB based on Paxinos and Watson atlas (Dolatshahi, Farbood et al. 2015).

The syringe was lowered into the brain at a rate of $2 \mathrm{~mm} / \mathrm{min}$. 6-OHDA was injected at a rate of $1 \mu \mathrm{l} / \mathrm{min}$, and the syringe was left in place for 5 min after injection before being drawn back at a rate of $2 \mathrm{~mm} / \mathrm{min}$ to guarantee thorough delivery (Fine, Stroebel et al. 2020, lancu, Mohapel et al. 2005).

\subsection{Apomorphine-Induced Rotation Test}

fourteen days after initial surgery, all animals were given an apomorphine hydrochloride (Sigma, USA) dissolved in normal saline containing $0.02 \%$ ascorbic acid $(0.5 \mathrm{mg} / \mathrm{kg})$ via subcutaneous (S.C) injection; to establish a behavioral effect and assess the lesion severity between the right and left-brain hemispheres and determine the integrity of nigrostriatal function. Animal rotation was monitored for 40 min and total turns contralateral to the lesion side were counted over the period mentioned (lancu, Mohapel et al. 2005).

\subsection{Treatment assay}

Sham and PD+veh groups received $20 \%$ DMSO in $80 \%$ saline solution (via intraperitoneal injection, i.p.). BA was dissolved in saline solution plus 20\% DMSO (Bi, Xu et al. 2007) freshly before use in doses of 0.5 , 5 , and $10 \mathrm{mg} / \mathrm{kg}$ (i.p.) in three other groups. Positive control group received Nacom (levodopa/carbidopa, $4: 1$ ratio) suspended in saline. The drug was administered orally through gavage at a dose of $20 \mathrm{mg} / \mathrm{kg}$ (Fleming, Delville et al. 2005). All groups were stood under treatment for seven consecutive days.

\subsection{Behavioral tests}

\subsection{1. bar test}

All behavioral experiments took place in a lightened room. Animals were adapted to the test room for $2 \mathrm{~h}$ prior to each experimental protocol. The cataleptic behavior was measured by the bar test and morpurgo test as previously described. In the bar test, the forelimbs were placed on a horizontal, wooden bar (diameter: $1.25 \mathrm{~cm}$; height: $10 \mathrm{~cm}$ ) and the time during which both forelimbs remained on the bar was determined up to a maximum of $30 \mathrm{~s}$. Both tests were repeated 3 and 6 min later and the mean of the three trials was used for analysis. Animals were returned to their home cage between tests (Prinssen, Colpaert et al. 2002).

\subsection{2. open-field test}

The open-field was carried out using a square wooden box measuring $80 \times 80 \times 40 \mathrm{~cm}$ divided by white lines into 16 equal squares $4 \times 4 \mathrm{~cm}$. Each rat was placed gently in the central area of the open-field and allowed to freely explore the area for $5 \mathrm{~min}$. The floor and walls were cleaned after testing each rat to eliminate possible bias due to odors left by previous rats. A video camera was fixed on the top of the box to record movement and behavior of rats (Abdelsalam and Safar 2015). The following behavioral parameters were then scored: total distance moved (TDM, $\mathrm{cm}$ ); total duration of mobility(s) and 
immobility(s); and frequency of rearing (as a measure of vertical activity). At the end of each session, rats were removed from the apparatus, and the experimental chamber was thoroughly cleaned with a damp cloth and dried (Dolatshahi, Farbood et al. 2015).

\subsubsection{Elevated plus maze test}

The plus-maze apparatus was a wooden, cross-shaped maze consisting of four arms arranged in the shape of a 'plus' sign. Two of the arms have no side or end walls (open arms; $50 \times 10 \mathrm{~cm}$ ). The other two arms have side walls and end walls, but are open on top (closed arms; 50×10×40 cm). Where the four arms intersect, there is a square platform of $10 \times 10 \mathrm{~cm}$. The maze was elevated to a height of $50 \mathrm{~cm}$ (Roohbakhsh, Moghaddam et al. 2007). The animals were placed in the central area of the EPM on day 14 , facing an open arm, and allowed to explore the apparatus for $5 \mathrm{~min}$. Before the next test, the maze was wiped clean with a $5 \%$ ethanol-water solution (Vieira, Bassani et al. 2019).

The total time spent in the open arms [OAT\% (the ratio of times spent in the open arms to total times spent in any arms $\times 100$ )] was used as a measure of anxiety. Entry was defined as all four paws in the arm. The number of entries into open arms [OAE\% (the ratio of entries into open arms to the total entries $x$ 100)] and the number of total arm entries was used as a measure of spontaneous locomotor activity (loc) (Sarkaki, Farbood et al. 2015).

\subsubsection{Passive Avoidance Test}

Passive avoidance task was evaluated by the shuttle box apparatus $(27 \times 14.5 \times 14 \mathrm{~cm})$ comprised of two illuminated and dark chambers with stainless steel bars $(2 \mathrm{~mm}$ in diameter and $1 \mathrm{~cm}$ in distance) in the floor and the sliding door $(8 \times 8 \mathrm{~cm})$ between them. On the first day, each rat was allowed to move freely inside the chambers (for10 $\mathrm{min}$ ) without receiving any electrical shock. On the next day, rats were located in the illuminated chamber, the sliding door was raised (30 s later) and the initial latency (IL) was recorded through an entering delay score to the dark chamber. After the door was closed, an electrical single shock $(50 \mathrm{~Hz}, 0.2 \mathrm{MA}, 3 \mathrm{~s}$ ) was transported to the apparatus and the rats were retained in the dark chamber for 2 min of consolidation time. In the 3rd day, the rats were positioned in the illuminated chamber again, the sliding door was moved up and delay time in entering into the dark chamber was recorded as memory latency (step-through latency) with the maximum time of $300 \mathrm{Sec}$ (Navabi, Sarkaki et al. 2018).

\subsubsection{Tail-Flick Test}

The spinally mediated thermal hyperalgesia was assessed by the tail-flick test as described previously. Rats were placed at the apparatus where a thermal stimulus was applied to the tail. The nociceptive threshold was recorded as the time the animal flicked its tail. A cutoff time of $10 \mathrm{~s}$ was used to prevent tissue damage. The latency of flick response was measured in seconds, and each animal was tested three times, with 5 min between each trial (Nascimento, Bariotto-Dos-Santos et al. 2018).

\subsection{Removing the Brain}


At the end of experiments, the rats were sacrificed after deep anesthesia. The head of the rat was placed on ice, and the brain was quickly removed. The brain was washed with pre-cooled saline, and then frozen in a freezer $\left(-80^{\circ} \mathrm{C}\right)$ until used. Then $200 \mathrm{mg}$ of brain tissue was homogenized in cold $\mathrm{KCl}$ solution $(1.5 \%)$ to give a $10 \%$ homogenate suspension and used for measuring the level of MDA, GPX, SOD, BDNF and IL10, according to the instructions of the Biochemical ELISA kits (Zellbio, Germany) (Mansouri, Farbood et al. 2013).

\subsection{Statistical Analysis}

The data were expressed as means \pm S.E.M. and were analyzed statistically by one-way ANOVA, followed by post hoc LSD test. Statistical significance was set at $p<0.05$. All statistics in this study were performed using GraphPad Prism software program (version 7, GraphPad Software Inc., San Diego, USA).

\section{Results}

\subsection{Apomorphine induced circling behavior}

As shown in Figure 1A, two weeks after surgery (before beginning of treatments), apomorphine induced contralateral turns were increased significantly in 6-OHDA lesioned groups when compared to sham group ( ${ }^{\star * \star} P<0.001$ ). Four weeks after surgery (after

treatments), the number of contralateral turns observed in treated groups (LD $20 \mathrm{mg} / \mathrm{kg} \& B A 10 \mathrm{mg} / \mathrm{kg}$ ) decreased significantly as compared to PD group (\#\#\#P<0.001 \& \#P<0.05 respectively), no difference was found among BA $5 \mathrm{mg} / \mathrm{kg} \&$ BA $0.5 \mathrm{mg} / \mathrm{kg}$ treated groups and PD group.

\subsection{Bar test}

As shown in Figure 1B, 6-OHDA induced a remarkable increase in rats' paw immobility after 3 weeks' post-surgery in bar test, which could be reversed by $10 \mathrm{mg} / \mathrm{kg}$ betulinic acid $(P<0.001)$, however it did not completely inhibit catalepsy. The bar test scores also showed a significant decrease in catatonic responses in levodopa treated group compared to sham treated group $(P<0.001)$ but no difference was found among BA $5 \mathrm{mg} / \mathrm{kg} \&$ BA $0.5 \mathrm{mg} / \mathrm{kg}$ treated groups and PD group.

\subsection{Open field}

The open-field test was conducted to examine locomotor activity and anxiety-related behaviors. As shown in Fig. 2, LD treated and BA10 treated rats displayed significantly lower numbers of crossing (Fig. 2A) \& rearings (Fig. 2B) $(P<0.001)$ compared to sham-operated rats. No differences were found between the LD and BA10 groups in crossing and rearing frequency after treatment. Both PD and BA10 treated groups also showed a reduction in grooming frequency (Fig. $2 \mathrm{C})(P<0.001 \& * P<0.05 \mathrm{vs}$. sham group respectively) while a meaningful reduction was not recognized in LD treated group in grooming. None of treated groups showed a significant difference in grooming frequency compared to PD group. There was a significant difference in immobility time among the PD and BA10 treated groups versus sham group 
(Fig. 2D) $(P<0.001)$, however LD treated group was the only group which showed a remarkable difference compared to PD group.

\subsection{Elevated Plus Maze}

Three weeks after surgery, 6-OHDA decreased the percentage of entries into the open arms of the elevated plus maze (Fig. 3A), $P<0.05$ ). Moreover, 6-OHDA-treated rats, tended to spend less time on the open arms as compared to sham group (Fig. 3B), $P<0.001)$. Administration of either betulinic acid $(10 \mathrm{mg} / \mathrm{kg})$ or Ldopa didn't change the number of entries into the open arms. The amount of time spent into open arms did not show any significant difference in LD group compared to PD group however BA10 treated group tended to spend less time in open arms in comparison with PD group $(P<0.001)$.

\subsection{Passive avoidance test}

Figure 4(A) shows the protective effects of BA treatment on the step through latency (STL) in PD rats. STL significantly declined in PD group in comparison to the sham operated group ( $\left.{ }^{* \star *} P<0.001\right)$. Daily intraperitoneal injection of L-dopa $(20 \mathrm{mg} / \mathrm{kg})$ and betulinic acid $(0.5,5$ and $10 \mathrm{mg} / \mathrm{kg})$ for 7 days to different treated groups dramatically increased the STL parameter compared with PD rats $(\# P<0.05$, $\# \# P<0.01 \& \# \# \#>0.001$ vs. PD group).

\subsection{Tail Flick}

As shown in figure 4(B) there was a significant decrease in nociception response in PD rats, 3 weeks after surgery ( $P<0.01$ vs. sham group). Administration of L-dopa and betulinic acid had no significant effect on nociception response in comparison with PD group.

\subsection{Biomarkers of oxidative stress and neurochemical alterations}

We further investigated the effect of BA on neurotoxin-induced DA neuronal degeneration by examining the level of MDA, a marker of lipid peroxidation in oxidative stress. As shown in figure 5, 6-OHDA stimulated massive MDA production in the serum of PD rats compared with those in the sham-group (A) $\left({ }^{\star} P<0.05\right)$. Treatment with BA abolished the increased MDA formation in LD $20 \mathrm{mg} / \mathrm{kg}$ and BA $10 \mathrm{mg} / \mathrm{kg}$ ( $\# P<0.05 \& \# \# P<0.01$ vs. PD group respectively) but it didn't show any positive effect in BA 0.5 \& 5 $\mathrm{mg} / \mathrm{kg}$, additionally administration of both LD \& BA remarkably attenuated the reduction of GPX $\square O D$ activity in the brain of 6-OHDA-injured PD model rats (B \& C) .As it has been shown, BA10 mg/kg increased the activity of GPX and SOD in rat brain ( $\# P<0.05$ and $\# \# \# P<0.001$ vs. PD group respectively) but there was no significant difference in GPX and SOD activity between BA 0.5, BA $5 \mathrm{mg} / \mathrm{kg}$ and PD group, however it seems to have improved with increasing dose. Treatment with LD caused a significant increase in GPX and SOD activity compared to PD group, ( $P<<0.05$ and $\# \# \# P<0.001$ respectively).

\subsection{Neurotrophic levels:}


Figure 6 shows the effects of betulinic acid and L-Dopa on brain-derived neurotrophic factor $(P g / m L)$ level in the striatum. Analyzed data revealed that BDNF level was considerably decreased in PD rats in comparison with the sham group $(P<0.001)$. It increased significantly in the LD $(P<0.001)$ and BA (10 $\mathrm{mg} / \mathrm{kg}, P<0.001)$ groups and there was no significant difference in BDNF level between BA 5 \& $0.5 \mathrm{mg} / \mathrm{kg}$ groups versus PD group.

\subsection{Neuroinflammation:}

Administration of 6-OHDA induced significant increase in rat brain IL-10 compared to the sham group $(\star \star P<0.01$, Fig. 7). Post hoc comparisons revealed that the increase of IL-10 levels induced by 6-OHDA was significantly prevented by administration of betulinic acid $10 \mathrm{mg} / \mathrm{kg}(\# \# P<0.01)$, but administration of L-dopa/Carbidopa(20mg/kg) to 6-OHDA-treated mice induced non-significant effect on the level of IL10.

\section{Discussion}

It was demonstrated that induction of PD model by 6-OHDA not only leads to an increased contralateral rotation, passive avoidance memory and behavioral impairment after MFB lesioning, but also caused a significant disruption in some of the important factors in the brain. In the present study, we have shown that betulinic acid as a potential neuroprotective agent against 6-OHDA induced neurotoxicity in rats.

Many researches have confirmed that MFB lesion could in fact enhance apomorphine-induced rotation (Kelly, Jenner et al. 1984), motor dysfunction (Antunes, Ladd et al. 2021) and memory impairments which is associated with loss of neurons and certain functions in the basal forebrain (Auld, Kornecook et al. 2002). In this study, unilateral degradation, induced by infusions of 6-OHDA into the MFB. It is common to wait 3 weeks after surgery for a stable nigrostriatal lesion development before using the lesioned animals for further analysis (Rosa, Di Censo et al. 2020). Similarly, in our experiment, rotatory behavior was assessed first in order to prove the PD related physiological impairments and confirmed the PD-model preparation in the experimental groups and the final analysis was performed 3 weeks after operation. we demonstrated that after 14 days, the 6-OHDA-treated rats showed significant apomorphine-induced contralateral rotation as compared to the control group. In following, neurobehavioral assessments (passive avoidance and catalepsy test, anxiety, locomotion and nociception) were evaluated in the experimental groups.

As the result, our findings cleared that, the ability of betulinic acid as a potential neuroprotective agent against 6-OHDA induced neurotoxicity. The affection of BA was shown to be dose dependent and at 10 $\mathrm{mg} / \mathrm{kg}$ dose was even more significantly potent than standard PD-drug such as LDOPA (20 mg/kg).

L-dopa is considered as the golden choice in the treatment of Parkinsonism. However, due to short halflife, various side effects, made many physicians not recommend its use until there is compelling need of the patients for such treatment. Herbal medicine has been widely used for clinical management of various diseases in human history instead (Farnsworth, Akerele et al. 1985). 
In various PD models, a-synuclein accumulation is toxic, particularly because it aggregates and blocks the cellular functions that support degradation of these aggregates, and thereby results in neuronal degeneration (Wang, Nguyen et al. 2016). These effects may be associated with dysregulation of PDrelated chaperones, downregulation of the degradation system, and rapid loss of whole cell homeostasis (Aflaki, Borger et al. 2016) The compound 6-OHDA is a specific neurotoxin that interferes with catecholamine neurons via the dopamine active transporter. When 6-OHDA is injected into the MFB or neo-striatum of animal brains, it causes irreversible damage to DA neurons in the ventral midbrain. This consistent loss of dopamine innervation which is associated with a range of behavioral deficits (Cai, Ye et al. 2016).

Multiple lines of evidence suggest that BA has broad-spectrum actions and is important in diverse biological pathways. For example, BA has been reported to possess anticancer, anti-inflammatory, antidiabetic and antihyperlipidemic activities (Kim, Lee et al. 2012, Silva, Oliveira et al. 2016, Bildziukevich, Rárová et al. 2018, Zeng, Yu et al. 2018) as well as the protective effect against ischemic complications and a potential therapy for Alzheimer's disease, ischemia, and other nervous diseases (Jiao, Zhu et al. 2016), The latter is due to its capability of penetrating through blood-brain barrier and improving functional recovery through its antioxidant effects (Deng, Ma et al. 2019).

Previous studies have found that Betulin which is one of the derivatives of betulinic acid attenuates DA neurons degeneration, reduces human a-synuclein, and protein accumulation, thereby blocking its toxic effect in cells (Deng, Purtell et al. 2017). In addition, it has been shown that pretreatment by betulinic acid in AD-induced rats improved neurobehavioral and cognitive impairments. Behavioral and memory impairment are direct consequence of oxidative stress. BA was found to inhibit both cholinesterases in a dual and moderate function leading to higher acetylcholine levels and improved cognitive performances in AD disturbance and improvements in memory and motor functions (Jamila, Khairuddean et al. 2015). Our data also confirmed the positive effects of BA on memory in shuttle box and behavioral responses in bar test and morporgo.

In addition, a survey elucidated the antinociceptive activity of Betulinic acid in neuropathic pain in preclinical rat models of chemotherapy-induced peripheral neuropathy (CIPN), HIV sensory neuropathy and a mouse model of partial sciatic nerve ligation through targeting low-voltage-gated calcium channels (Bellampalli, Ji et al. 2019).

Anxiety is another common non-motor feature of PD and exerts a significant impact on patient's quality of life and may complicate the treatment. In this line, Tadaiesky et. al (Tadaiesky, Dombrowski et al. 2008). showed that 3 weeks after surgery, 6-OHDA-lesioned animals decreased significantly the percentage of entries into the open arms of the EPM. In addition, Chen et al (Chen, Liu et al. 2011) showed that 6-OHDA-lesioned rats presented a reduction in the time spent in the open arms of an EPM. The same anxiety-like behavior was observed by Vieira et. al., indicating an anxiety-like behavior in 6OHDA-lesioned rats (Vieira, Bassani et al. 2019). Some researchers have reported that anxiety-like behaviors may be related to monoaminergic alterations (Faggiani, Naudet et al. 2018). 
our data show that in our experiment, similar results were observed after 6-OHDA administration and 6OHDA-lesioned rats had a reduction in the time spent in the open arms of the EPM indicating an anxietylike behavior however no amelioration by chronic treatment with BA either in nociceptive or in anxiety like behavior response in PD rats recognized.

Moreover, in our findings, betulinic acid $(10 \mathrm{mg} / \mathrm{kg})$ caused an increase in the level of SOD, GPX, suggesting that the protective effects of BA on neurotoxin-induced neuronal degeneration maybe mediated by its antioxidative action. Moreover, it may be due to an increase in the level of MDA \& BDNF and a decrease in the level of anti-inflammatory factor IL-10 in betulinic acid treated groups that were recognized in this study.

DA neurons are more vulnerable to oxidative stress in the 6-OHDA model because this compound generates reactive oxygen species and release inflammatory factors (Han, Shen et al. 2020), which are the primary regulators of neuronal apoptosis and death (Kesh, Kannan et al. 2021). Several studies have highlighted the role of betulinic acid in suppressing reactive oxygen species, neuro anti-inflammation, and antioxidant functions which has widely been described in physiological and cancer papers (Dash, Chattopadhyay et al. 2015), stress by boosting the endogenous antioxidant production in both macrophages and astrocytes and reducing lipid peroxidation (Blaževski, Petković et al. 2013). For example, it has been found that BA pretreatment can prevent kidney damage by recovering the imbalance of inflammatory mediators, oxidants, and antioxidants induced by cecal ligation puncture (Lingaraju, Pathak et al. 2015). Also it has been revealed by some studies that the greatest production of ROS, which contributes to oxidative damage plays a key role in attacking all macromolecules, including lipids, proteins and nucleic acids, leading to defects in their physiological functions. Consequently, the defects in these macromolecules enhance the production of ROS and ultimately neuronal damage. The interaction between these various mechanisms forms a positive feedback loop that drives the progressive loss of dopaminergic neurons in PD, and oxidative stress-mediated neuronal damage appears to serve a central role in the neurodegenerative process (Guo, Zhao et al. 2018). BA has found to be able to improve the antioxidant capacity of tissues by decreasing the content of MDA and increasing the levels of GSH-Px and SOD in thymocytes (Yi, Zhu et al. 2015), and GPX activity in kidney (Prakash, Surendran et al. 2018).

Brain-derived neurotrophic factor (BDNF) is already known to enhance neurogenesis in normal conditions by increasing the generation of immature neuroblasts, differentiation and survival of neural progenitors(Kaundal, Zameer et al. 2018). It also promotes glutamate release and effects synaptic transmission and plasticity (Martin and Finsterwald 2011) and have therefore attracted keen interest in relation to neurodegenerative disorders such as PD. BDNF prevents neuronal degeneration of the lesioned nigro-striatal system in vivo, and improves motor deficits. In previous studies, 6-OHDA-treated rats showed a depletion in the BDNF levels which was significantly restored after implementing an antioxidant drug treatment (Goes, Jesse et al. 2018).

Neuroinflammation is an important risk factor that may contribute to PD pathogenesis, since PD patients suffer from chronic inflammation that probably precedes neurodegeneration and cytokines produced by 
activated microglia in the substantia nigra (SN) and putamen in the course of PD (Porro, Cianciulli et al. 2020). A recent report showed increased peripheral concentrations of IL-6, IL-1 3 , TNFa, IL-2 and IL-10 in patients with PD (Qin, Zhang et al. 2016). Similarly, in the analyses of newly diagnosed PD patients, IL-1 $\beta$, TNFa, IL-2 and IL-10 resulted elevated (Williams-Gray, Wijeyekoon et al. 2016).

Anti-inflammatory activity of betulinic acid is presented as two phases: early and late phase. In the early phase, the release of mediators of acute inflammation such as histamine, serotonin and bradykinin occur, while prostaglandins are released in the late phase of inflammation. The anti-inflammatory activity of this compound was more profound after 2 hours' post-injection of the phlogistic agent. This suggests that the mechanism of anti-inflammation is mediated more via inhibition of prostaglandin synthesis and/or release (Oyebanji, Saba et al. 2014).

\section{Conclusion}

In summary, betulinic acid which seems to have a dose dependently manner, attenuated 6-OHDA-induced motor and cognitive deterioration, and improved neurochemical molecular alterations in the present study. The current study suggests the therapeutic potential of betulinic acid in cognitive and motor disorders such as PD.

\section{Declarations}

\section{Acknowledgments}

This work was supported by a grant (APRC-9611) from Ahvaz Physiology Research Center, funded by the Vice Chancellor of Research, Ahvaz Jundishapur University of Medical Sciences (Ahvaz, Iran).

\section{Author contributions:}

All authors have participated in (a) conception and design, or analysis and interpretation of the data; (b) drafting the article or revising it critically for important intellectual content; and (c) approval of the final version.

1. MA analyzed the electrophysiological data and contributed in performing behavioral tests and writing the manuscript.

2. AS designed, guided, and supervised the project and monitored the electrophysiological records.

3. YF was responsible for monitoring and approving the behavioral tests in different experimental groups.

4. MR was responsible for the biochemical factors analyses.

5. MB revised the article.

\section{Funding}


The authors did not receive any financial support from any organization for the submitted work. The authors have no affiliation with any organization with a direct or indirect financial interest in the subject matter discussed in the manuscript.

\section{Data availability}

The data that supports the findings of this study could be accessed through the corresponding author upon reasonable request.

\section{Ethics approval}

This article does not contain any studies with human participants performed by any of the authors. The ethics governing the use and conduct of experiments on animals were strictly observed, and all the procedures used in this study were done according to the National Institute of Health $(\mathrm{NIH})$ and were approved by the Local Ethics Committee of Ahvaz Jundishapur University of Medical Sciences (AJUMS) (ethic code: IR.AJUMS.REC.1396.662)

\section{Conflict of interest}

The authors declare that there is no conflict of interest.

\section{References}

Aarsland, D. and M. G. Kramberger (2015). "Neuropsychiatric symptoms in Parkinson's disease." Parkinsons Dis. 5(3): 659-667. https://doi.org/10.3233/JPD-150604.

Abdelsalam, R. M. and M. M. Safar (2015). "Neuroprotective effects of vildagliptin in rat rotenone Parkinson's disease model: role of RAGE-NF KB and Nrf2-antioxidant signaling pathways." neurochemist. 133(5): 700-707. https://doi.org/10.1111/jnc.13087.

Aflaki, E., D. K. Borger, N. Moaven, B. K. Stubblefield, S. A. Rogers, S. Patnaik, F. J. Schoenen, W. Westbroek, W. Zheng and P. Sullivan (2016). "A new glucocerebrosidase chaperone reduces a-synuclein and glycolipid levels in iPSC-derived dopaminergic neurons from patients with Gaucher disease and parkinsonism." Neurosci. 36(28): 7441 -7452. https://doi.org/10.1523/JNEUROSCI.0636-16.2016.

Antunes, M. S., F. V. L. Ladd, A. A. B. L. Ladd, A. L. Moreira, S. P. Boeira and L. C. Souza (2021). "Hesperidin protects against behavioral alterations and loss of dopaminergic neurons in 6-OHDA-lesioned mice: the role of mitochondrial dysfunction and apoptosis." Metab Brain Dis. 36(1): 153167. https://doi.org/10.1007/s11011-020-00618-y.

Auld, D. S., T. J. Kornecook, S. Bastianetto and R. Quirion (2002). "Alzheimer's disease and the basal forebrain cholinergic system: relations to $\beta$-amyloid peptides, cognition, and treatment strategies." Prog neurobiol. 68(3): 209-245. https://doi.org/10.1016/S0301-0082(02)00079-5. 
Bellampalli, S. S., Y. Ji, A. Moutal, S. Cai, E. K. Wijeratne, M. A. Gandini, J. Yu, A. Chefdeville, A. Dorame and L. A. Chew (2019). "Betulinic acid, derived from the desert lavender Hyptis emoryi, attenuates paclitaxel-, HIV-, and nerve injury-associated peripheral sensory neuropathy via block of N-and T-type calcium channels." Pain. 160(1): 117. https://dx.doi.org/10.1097\%2Fj.pain.0000000000001385.

Betarbet, R., T. B. Sherer, G. MacKenzie, M. Garcia-Osuna, A. V. Panov and J. T. Greenamyre (2000). "Chronic systemic pesticide exposure reproduces features of Parkinson's disease." Nat Neurosci. 3(12): 1301-1306. http://neurosci.nature.com/.

Bhattacharya, S., A. Bhattacharya, A. Kumar and S. Ghosal (2000). "Antioxidant activity ofBacopa monniera in rat frontal cortex, striatum and hippocampus." Phytother Res. 14(3): 174-179. https://doi.org/10.1002/(SICI)1099-1573(200005)14:3\%3C174::AID-PTR624\%3E3.0.CO;2-O.

Bi, Y., J. Xu, X. Wu, W. Ye, S. Yuan and L. Zhang (2007). "Synthesis and cytotoxic activity of 17-carboxylic acid modified 23-hydroxy betulinic acid ester derivatives." Bioorg Med Chem Lett. 17(5): 1475-1478. https://doi.org/10.1016/j.bmcl.2006.09.096.

Bildziukevich, U., L. Rárová, D. Šaman and Z. Wimmer (2018). "Picolyl amides of betulinic acid as antitumor agents causing tumor cell apoptosis." Eur J Med Chem 145: 41-50. https://doi.org/10.1016/j.ejmech.2017.12.096.

Blandini, F., M.-T. Armentero and E. Martignoni (2008). "The 6-hydroxydopamine model: news from the past." Parkinsonism Relat Disord. 14: S124-S129. https://doi.org/10.1016/j.parkreldis.2008.04.015.

Blaževski, J., F. Petković, M. Momčilović, R. Paschke, G. N. Kaluđerović, M. M. Stojković and D. Miljković (2013). "Betulinic acid regulates generation of neuroinflammatory mediators responsible for tissue destruction in multiple sclerosis in vitro." Acta Pharmacol Sin. 34(3): 424431. https://doi.org/10.1038/aps.2012.181.

Cai, P., J. Ye, J. Zhu, D. Liu, D. Chen, X. Wei, N. R. Johnson, Z. Wang, H. Zhang and G. Cao (2016). "Inhibition of endoplasmic reticulum stress is involved in the neuroprotective effect of bFGF in the 6OHDA-induced Parkinson's disease model." Aging Dis. 7(4): 336.

https://dx.doi.org/10.14336\%2FAD.2016.0117.

Chen, L., J. Liu, U. Ali, Z. H. Gui, C. Hou, L. L. Fan, Y. Wang and T. Wang (2011). "Chronic, systemic treatment with a metabotropic glutamate receptor 5 antagonist produces anxiolytic-like effects and reverses abnormal firing activity of projection neurons in the basolateral nucleus of the amygdala in rats with bilateral 6-OHDA lesions." Brain Res Bull. 84(3): 215-223.

https://doi.org/10.1016/j.brainresbull.2011.01.005.

Dash, S. K., S. Chattopadhyay, T. Ghosh, S. S. Dash, S. Tripathy, B. Das, B. G. Bag, D. Das and S. Roy (2015). "Self-assembled betulinic acid protects doxorubicin induced apoptosis followed by reduction of 
ROS-TNF-a-caspase-3 activity." Biomed Pharmacother. 72: 144-157.

https://www.sciencedirect.com/science/journal/07533322/72/supp/C.

De Jesús-Cortés, H., A. D. Miller, J. K. Britt, A. J. DeMarco, M. De Jesús-Cortés, E. Stuebing, J. Naidoo, E. Vázquez-Rosa, L. Morlock and N. S. Williams (2015). "Protective efficacy of P7C3-S243 in the 6hydroxydopamine model of Parkinson's disease." NPJ Parkinson's dis. 1(1): 1-

6. https://doi.org/10.1038/npjparkd.2015.10.

Deng, G., C. Ma, H. Zhao, S. Zhang, J. Liu, F. Liu, Z. Chen, A. T. Chen, X. Yang and J. Avery (2019). "Antiedema and antioxidant combination therapy for ischemic stroke via glyburide-loaded betulinic acid nanoparticles." Theranostics. 9(23): 6991. https://dx.doi.org/10.7150\%2Fthno.35791.

Deng, Z., K. Purtell, V. Lachance, M. S. Wold, S. Chen and Z. Yue (2017). "Autophagy receptors and neurodegenerative diseases." Trends Cell Biol. 27(7): 491-504. https://doi.org/10.1016/j.tcb.2017.01.001.

do Nascimento, G. C., D. P. Ferrari, F. S. Guimaraes, E. A. Del Bel, M. Bortolanza and N. C. Ferreira-Junior (2020). "Cannabidiol increases the nociceptive threshold in a preclinical model of Parkinson's disease." Neuropharmacology_163: 107808. https://doi.org/10.1016/j.neuropharm.2019.107808.

Dolatshahi, M., Y. Farbood, A. Sarkaki, S. M. T. Mansouri and A. Khodadadi (2015). "Ellagic acid improves hyperalgesia and cognitive deficiency in 6-hydroxidopamine induced rat model of Parkinson's disease." Iran J Basic Med Sci. 18(1): 38.

Domenici, R. A., A. C. P. Campos, S. T. Maciel, M. B. Berzuino, M. S. Hernandes, E. T. Fonoff and R. L. Pagano (2019). "Parkinson's disease and pain: Modulation of nociceptive circuitry in a rat model of nigrostriatal lesion." Exp Neurol. 315: 72-81. https://doi.org/10.1016/j.expneurol.2019.02.007.

Faggiani, E., F. Naudet, M. L. Janssen, Y. Temel and A. Benazzouz (2018). "Serotonergic neurons mediate the anxiolytic effect of I-DOPA: neuronal correlates in the amygdala." Neurobiol Dis. 110: 20-28. https://doi.org/10.1016/j.nbd.2017.11.001.

Faivre, F., A. Joshi, E. Bezard and M. Barrot (2019). "The hidden side of Parkinson's disease: Studying pain, anxiety and depression in animal models." Neurosci Biobehav. 96: 335-352.

https://doi.org/10.1016/j.neubiorev.2018.10.004.

Farnsworth, N. R., O. Akerele, A. S. Bingel, D. D. Soejarto and Z. Guo (1985). "Medicinal plants in therapy." Bull World Health Organ. 63(6): 965.

Fine, J. M., B. M. Stroebel, K. A. Faltesek, K. Terai, L. Haase, K. E. Knutzen, J. Kosyakovsky, T. J. Bowe, A. K. Fuller and W. H. Frey (2020). "Intranasal delivery of low-dose insulin ameliorates motor dysfunction and dopaminergic cell death in a 6-OHDA rat model of Parkinson's Disease." Neurosci Lett. 714: 134567. https://doi.org/10.1016/j.neulet.2019.134567. 
Fleming, S. M., Y. Delville and T. Schallert (2005). "An intermittent, controlled-rate, slow progressive degeneration model of Parkinson's disease: antiparkinson effects of Sinemet and protective effects of methylphenidate." Behav Brain Res. 156(2): 201-213. https://doi.org/10.1016/j.bbr.2004.05.024.

Goes, A. T., C. R. Jesse, M. S. Antunes, F. V. L. Ladd, A. A. L. Ladd, C. Luchese, N. Paroul and S. P. Boeira (2018). "Protective role of chrysin on 6-hydroxydopamine-induced neurodegeneration a mouse model of Parkinson's disease: Involvement of neuroinflammation and neurotrophins." Chem Biol Interact. 279: 111120. https://doi.org/10.1016/j.cbi.2017.10.019.

Gonçalves, D. F., A. A. Courtes, D. D. Hartmann, P. C. da Rosa, D. M. Oliveira, F. A. Soares and C. L. Dalla Corte (2019). "6-Hydroxydopamine induces different mitochondrial bioenergetics response in brain regions of rat." Neurotoxicology. 70: 1-11. https://doi.org/10.1016/j.neuro.2018.10.005.

Guo, J. D., X. Zhao, Y. Li, G. R. Li and X. L. Liu (2018). "Damage to dopaminergic neurons by oxidative stress in Parkinson's disease." Int J Mol Med. 41(4): 1817-1825. https://doi.org/10.3892/ijmm.2018.3406.

Han, C., H. Shen, Y. Yang, Y. Sheng, J. Wang, W. Li, X. Zhou, L. Guo, L. Zhai and Q. Guan (2020). "Antrodia camphorata polysaccharide resists 6-OHDA-induced dopaminergic neuronal damage by inhibiting ROSNLRP3 activation." Brain Behav. 10(11): e01824. https://doi.org/10.1002/brb3.1824.

lancu, R., P. Mohapel, P. Brundin and G. Paul (2005). "Behavioral characterization of a unilateral 6-OHDAlesion model of Parkinson's disease in mice." Behav Brain Res. 162(1): 1-10. https://doi.org/10.1016/j.bbr.2005.02.023.

Jamila, N., M. Khairuddean, K. K. Yeong, H. Osman and V. Murugaiyah (2015). "Cholinesterase inhibitory triterpenoids from the bark of Garcinia hombroniana." J Enzyme Inhib Med Chem. 30(1): 133-139. https://doi.org/10.3109/14756366.2014.895720.

Jiao, S., H. Zhu, P. He and J. Teng (2016). "Betulinic acid protects against cerebral ischemia/reperfusion injury by activating the PI3K/Akt signaling pathway." Biomed Pharmacother . 84: 1533-1537. https://doi.org/10.1016/j.biopha.2016.11.028.

Kaundal, M., S. Zameer, A. K. Najmi, S. Parvez and M. Akhtar (2018). "Betulinic acid, a natural PDE inhibitor restores hippocampal cAMP/cGMP and BDNF, improve cerebral blood flow and recover memory deficits in permanent BCCAO induced vascular dementia in rats." Eur J Pharmacol. 832: 56-66. https://doi.org/10.1016/j.ejphar.2018.05.015.

Kelly, E., P. Jenner and C. Marsden (1984). "Behavioural effects mediated by unilateral nigral dopamine receptor stimulation in the rat." Exp Brain Res. 55(2): 243-252. https://doi.org/10.1007/BF00237275.

Kesh, S., R. R. Kannan and A. Balakrishnan (2021). "Naringenin alleviates 6-hydroxydopamine induced Parkinsonism in SHSY5Y cells and zebrafish model." Comp Biochem Physiol C: Toxicol Pharmacol. 239: 108893. https://doi.org/10.1016/j.cbpc.2020.108893. 
Kim, J., Y. S. Lee, C. S. Kim and J. S. Kim (2012). "Betulinic acid has an inhibitory effect on pancreatic lipase and induces adipocyte lipolysis." Phytother Res. 26(7): 1103-1106.

https://onlinelibrary.wiley.com/journal/10991573.

Lau, Y. S., G. Patki, K. Das-Panja, W. D. Le and S. O. Ahmad (2011). "Neuroprotective effects and mechanisms of exercise in a chronic mouse model of Parkinson's disease with moderate neurodegeneration." Eur J Neurosci. 33(7): 1264-1274. https://doi.org/10.1111/j.14609568.2011.07626.x.

Lingaraju, M. C., N. N. Pathak, J. Begum, V. Balaganur, H. D. Ramachandra, R. A. Bhat, M. Ram, V. Singh, K. Kandasamy and D. Kumar (2015). "Betulinic acid attenuates renal oxidative stress and inflammation in experimental model of murine polymicrobial sepsis." Eur J Pharm Sci. 70: 12-21. https://doi.org/10.1016/j.ejps.2015.01.001.

Mansouri, M. T., Y. Farbood, M. J. Sameri, A. Sarkaki, B. Naghizadeh and M. Rafeirad (2013).

"Neuroprotective effects of oral gallic acid against oxidative stress induced by 6-hydroxydopamine in rats." Food Chem. 138(2-3): 1028-1033. https://doi.org/10.1016/j.foodchem.2012.11.022.

Martin, J.-L. and C. Finsterwald (2011). "Cooperation between BDNF and glutamate in the regulation of synaptic transmission and neuronal development." Commun Integr Biol. 4(1): 14-16. https://doi.org/10.4161/cib.13761.

Nascimento, G., K. Bariotto-Dos-Santos, C. Leite-Panissi, E. Del-Bel and M. Bortolanza (2018). "Nociceptive response to I-DOPA-induced dyskinesia in hemiparkinsonian rats." Neurotox Res. 34(4): 799-807. https://doi.org/10.1007/s12640-018-9896-0.

Navabi, S. P., A. Sarkaki, E. Mansouri, M. Badavi, A. Ghadiri and Y. Farbood (2018). "The effects of betulinic acid on neurobehavioral activity, electrophysiology and histological changes in an animal model of the Alzheimer's disease." Behav Brain Res. 337: 99-106. https://doi.org/10.1016/j.bbr.2017.10.002.

Oyebanji, B. O., A. B. Saba and O. A. Oridupa (2014). "Studies on the anti-inflammatory, analgesic and antipyrexic activities of betulinic acid derived from Tetracera potatoria." Afr J Tradit Complement Altern Med. 11(1): 30-33. https://doi.org/10.4314/ajtcam.v11i1.5.

Planchard, M. S., M. A. Samel, A. Kumar and V. Rangachari (2012). "The natural product betulinic acid rapidly promotes amyloid- $\beta$ fibril formation at the expense of soluble oligomers." ACS Chem Neurosci. 3(11): 900-908. https://doi.org/10.1021/cn300030a.

Porro, C., A. Cianciulli and M. A. Panaro (2020). "The regulatory role of IL-10 in neurodegenerative diseases." Biomolecules 10(7): 1017. https://doi.org/10.3390/biom10071017. 
Prakash, B., A. Surendran, V. R. Chandraprabha, A. Pettamanna and H. N. R. Nair (2018). "Betulinic acid, natural pentacyclic triterpenoid prevents arsenic-induced nephrotoxicity in male Wistar rats." Comp Clin Pathol. 27(1): 37-44. https://doi.org/10.1007/s00580-017-2548-6.

Prinssen, E. P., F. C. Colpaert and W. Koek (2002). "5-HT1A receptor activation and anti-cataleptic effects: high-efficacy agonists maximally inhibit haloperidol-induced catalepsy." Eur J pharmacol. 453(2-3): 217221. https://doi.org/10.1016/S0014-2999(02)02430-5.

Qin, X.-Y., S.-P. Zhang, C. Cao, Y. P. Loh and Y. Cheng (2016). "Aberrations in peripheral inflammatory cytokine levels in Parkinson disease: a systematic review and meta-analysis." JAMA neurol. 73(11): 13161324. https://doi.org/10.1001/jamaneurol.2016.2742.

Razavinasab, M., A. Shamsizadeh, M. Shabani, M. Nazeri, M. Allahtavakoli, M. Asadi-Shekaari, S. Esmaeli-Mahani and V. Sheibani (2013). "Pharmacological blockade of TRPV 1 receptors modulates the effects of 6-OHDA on motor and cognitive functions in a rat model of $\mathrm{P}$ arkinson's disease." Fundam Clin Pharmacol. 27(6): 632-640. https://doi.org/10.1111/fcp.12015.

Real, C. C., P. C. Garcia and L. R. Britto (2017). "Treadmill exercise prevents increase of neuroinflammation markers involved in the dopaminergic damage of the 6-OHDA Parkinson's disease model." J Mol Neurosci. 63(1): 36-49. https://doi.org/10.1007/s12031-017-0955-4.

Roohbakhsh, A., A. H. Moghaddam, R. Massoudi and M. R. Zarrindast (2007). "Role of dorsal hippocampal cannabinoid receptors and nitric oxide in anxiety like behaviours in rats using the elevated plus-maze test." Clinical Exp Pharmacol Physiol. 34(3): 223-229. https://doi.org/10.1111/j.14401681.2007.04576.x.

Rosa, I., D. Di Censo, B. Ranieri, G. Di Giovanni, E. Scarnati, M. Alecci, A. Galante and T. M. Florio (2020). "Comparison between Tail Suspension Swing Test and Standard Rotation Test in revealing early motor behavioral changes and neurodegeneration in 6-OHDA hemiparkinsonian rats." Int J Mol Sci. 21(8): 2874. https://doi.org/10.3390/ijms21082874.

Sarkaki, A., Y. Farbood, M. Badavi, L. Khalaj, F. Khodagholi and G. Ashabi (2015). "Metformin improves anxiety-like behaviors through AMPK-dependent regulation of autophagy following transient forebrain ischemia." Metab brain dis. 30(5): 1139-1150. https://doi.org/10.1007/s11011-015-9677-x.

Schober, A. (2004). "Classic toxin-induced animal models of Parkinson's disease: 6-OHDA and MPTP." Cell Tissue Res. 318(1): 215-224. https://doi.org/10.1007/s00441-004-0938-y.

Silva, F. S., P. J. Oliveira and M. F. Duarte (2016). "Oleanolic, Ursolic, and Betulinic Acids as Food Supplements or Pharmaceutical Agents for Type 2 Diabetes: Promise or Illusion?" J Agric Food Chem. 64(15): 2991-3008. https://doi.org/10.1021/acs.jafc.5b06021. 
Souza, P., C. Rodrigues, A. Santiago, N. Lucas, G. G. Leitao and A. Galina Filho (2011). "Antioxidant activity of natural compounds of Stachytarpheta cayennensis by scavenger of mitochondrial reactive oxygen species." Rev Bras Farmacogn 21: 420-426. https://doi.org/10.1590/S0102$695 \times 2011005000050$.

Staudt, M. D., A. R. Di Sebastiano, H. Xu, M. Jog, S. Schmid, P. Foster and M. O. Hebb (2016). "Advances in Neurotrophic factor and cell-based therapies for Parkinson's disease: a mini-review." Gerontology. 62(3): 371-380. https://doi.org/10.1159/000438701.

Tadaiesky, M., P. Dombrowski, C. Figueiredo, E. Cargnin-Ferreira, C. Da Cunha and R. Takahashi (2008). "Emotional, cognitive and neurochemical alterations in a premotor stage model of Parkinson's disease." Neuroscience. 156(4): 830-840. https://doi.org/10.1016/j.neuroscience.2008.08.035.

Teixeira, M., C. Souza, A. Menezes, M. Carmo, A. Fonteles, J. Gurgel, F. Lima, G. Viana and G. Andrade (2013). "Catechin attenuates behavioral neurotoxicity induced by 6-OHDA in rats." Pharmacol Biochem Behav. 110: 1-7. https://doi.org/10.1016/j.pbb.2013.05.012.

Ungerstedt, U. (1968). "6-Hydroxy-dopamine induced degeneration of central monoamine neurons." Eur J Pharmacol. 5(1): 107-110. https://doi.org/10.1016/0014-2999(68)90164-7.

Uzar, E., H. Alp, M. U. Cevik, U. Fırat, O. Evliyaoglu, A. Tufek and Y. Altun (2012). "Ellagic acid attenuates oxidative stress on brain and sciatic nerve and improves histopathology of brain in streptozotocininduced diabetic rats." Neurol Sci. 33(3): 567-574. https://doi.org/10.1007/s10072-011-0775-1.

Vieira, J. C. F., T. B. Bassani, R. M. Santiago, G. d. O. Guaita, J. M. Zanoveli, C. da Cunha and M. A. Vital (2019). "Anxiety-like behavior induced by 6-OHDA animal model of Parkinson's disease may be related to a dysregulation of neurotransmitter systems in brain areas related to anxiety." Behav Brain Res. 371: 111981. https://doi.org/10.1016/j.bbr.2019.111981.

Wang, W., L. T. Nguyen, C. Burlak, F. Chegini, F. Guo, T. Chataway, S. Ju, O. S. Fisher, D. W. Miller and D. Datta (2016). "Caspase-1 causes truncation and aggregation of the Parkinson's disease-associated protein a-synuclein." Proc Natl Acad Sci. 113(34): 9587-9592. https://doi.org/10.1073/pnas. 1610099113.

Williams-Gray, C. H., R. Wijeyekoon, A. J. Yarnall, R. A. Lawson, D. P. Breen, J. R. Evans, G. A. Cummins, G. W. Duncan, T. K. Khoo and D. J. Burn (2016). "S erum immune markers and disease progression in an incident $\mathrm{P}$ arkinson's disease cohort (ICICLE-PD)." Mov Disord. 31(7): 995-1003. https://doi.org/10.1002/mds.26563.

Yi, J., R. Zhu, J. Wu, J. Wu and Z. Tan (2015). "Ameliorative effect of betulinic acid on oxidative damage and apoptosis in the splenocytes of dexamethasone treated mice." Int Immunopharmacol. 27(1): 85-94. https://doi.org/10.1016/j.intimp.2015.04.050. 
Yogeeswari, P. and D. Sriram (2005). "Betulinic acid and its derivatives: a review on their biological properties." Curr Med Chem. 12(6): 657-666. https://doi.org/10.2174/0929867053202214.

Zeng, A. Q., Y. Yu, Y. Q. Yao, F. F. Yang, M. Liao, L. J. Song, Y. L. Li, Y. Yu, Y. J. Li, Y. L. Deng, S. P. Yang, C. J. Zeng, P. Liu, Y. M. Xie, J. L. Yang, Y. W. Zhang, T. H. Ye and Y. Q. Wei (2018). "Betulinic acid impairs metastasis and reduces immunosuppressive cells in breast cancer models." Oncotarget. 9(3): 3794-3804. https://dx.doi.org/10.18632\%2Foncotarget.23376.

\section{Figures}



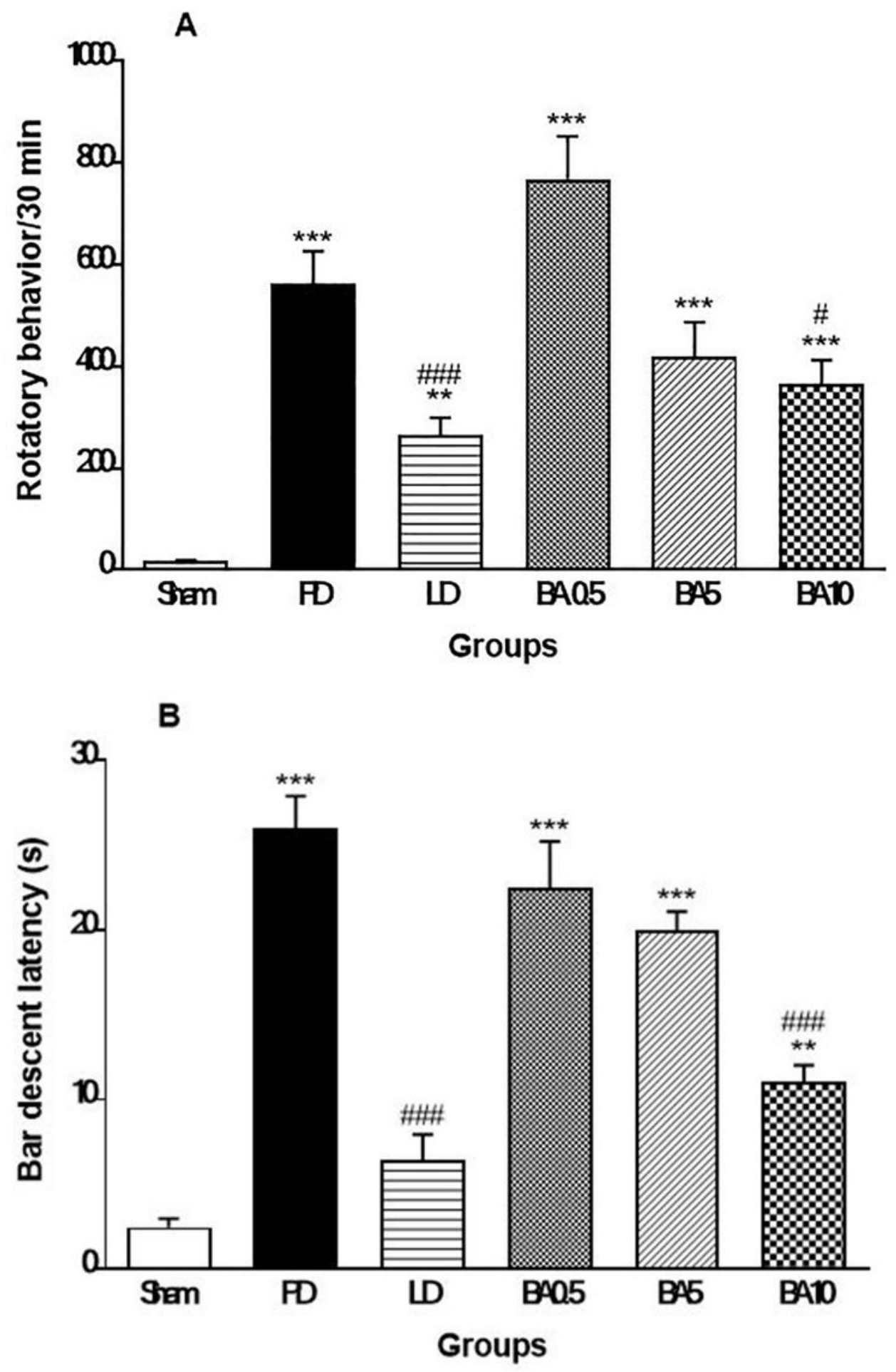

Figure 1

The effects of LD\& BA on rotatory behavior (A) and bar descent latency (B) in PD rats. The results were expressed as mean \pm SEM $(n=8)$. Data analyzed by one-way ANOVA followed by Tukey's post hoc test for among multiple groups comparison. ${ }^{\star *} \mathrm{P}<0.01 \& * \star \star P<0.001$ vs. sham group. \#P<0.05\&\#\#\#P<0.001 vs. PD group after 3 weeks' post-surgery. (PD=Lesion group, LD=LDOPA $20 \mathrm{mg} / \mathrm{kg}$ treated group, BA0.5, BA5, BA10 = Betulinic acid $0.5 \mathrm{mg} / \mathrm{kg}, 5 \mathrm{mg} / \mathrm{kg}, 10 \mathrm{mg} / \mathrm{kg}$ treated groups) 

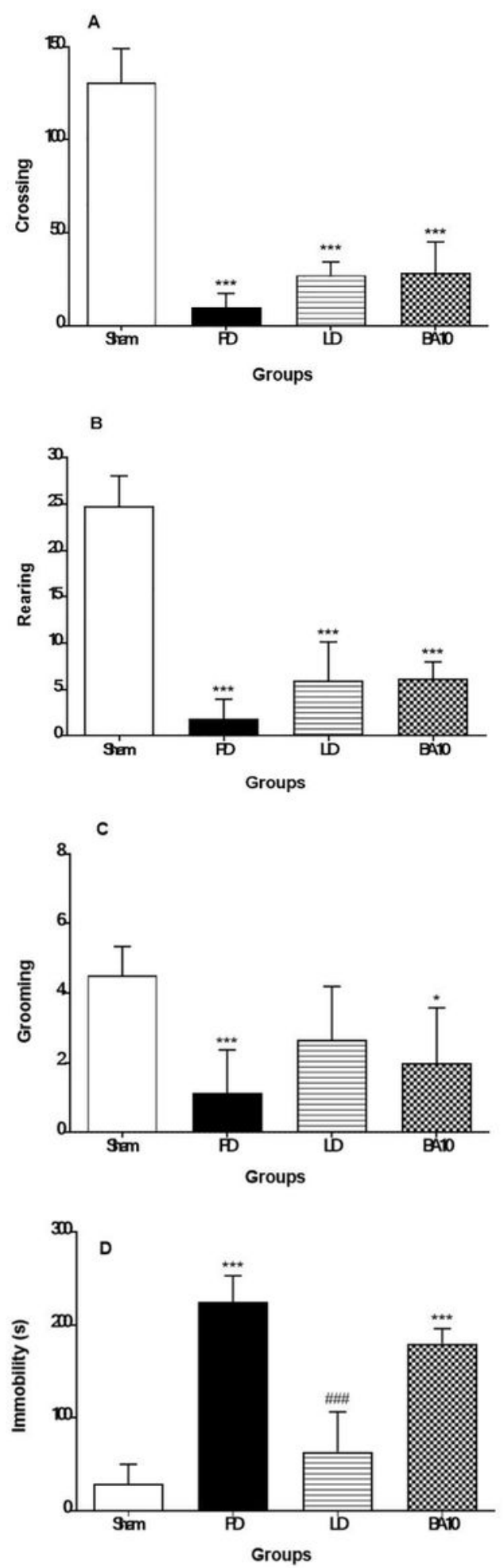

Figure 2

The effects of betulinic acid and L-dopa on locomotor activity and anxiety-related behaviors in PD rats. Rats were evaluated with an open-field test based on the number of crossing (A) rearings (B), grooming (C) and immobility time (D). The results were expressed as mean \pm SEM $(n=8)$. Data analyzed by one-way ANOVA followed by Tukey's post hoc test for among multiple groups comparison. ${ }^{\star} P<0.05 \&{ }^{*} * \mathrm{P}<0.001$ 
vs. sham group, \#\#\#P<0.001 vs. PD group after 3 weeks' post-surgery. (PD=lesion group, LD=LDOPA $20 \mathrm{mg} / \mathrm{kg}$ treated group, BA10 = Betulinic acid $10 \mathrm{mg} / \mathrm{kg}$ treated group)
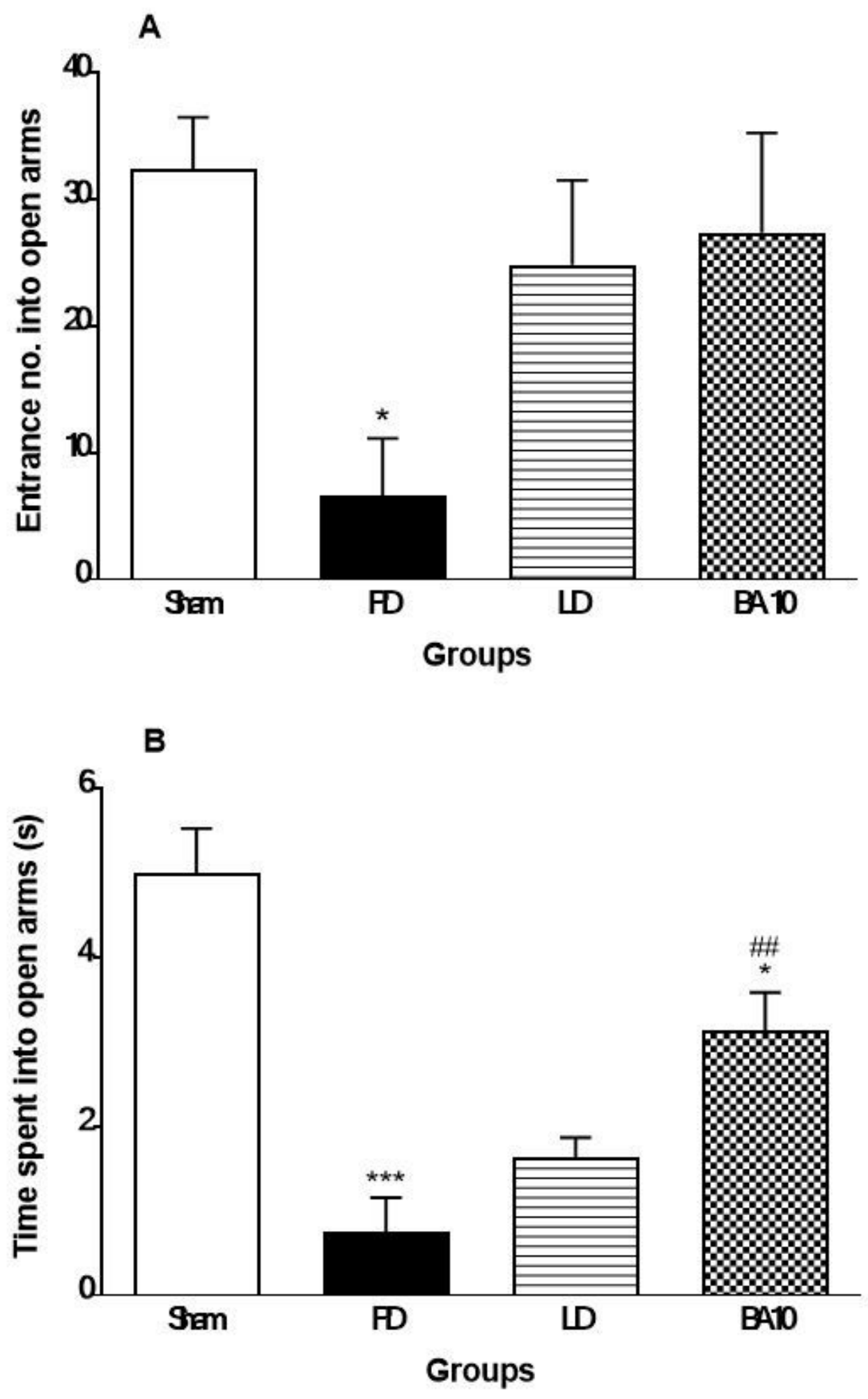

Figure 3

The effects of Betulinic acic and Ldopa on Elevated Plus Maze (fig7 \& fig8), in PD rats. rats were evaluated based on the percentage entries into the open arms (A) \% Time in open arms. (B) \%. The results were expressed as mean \pm SEM $(n=8)$. Data analyzed by one-way ANOVA followed by Tukey's post hoc 
test for among multiple groups comparison. ${ }^{*} \mathrm{P}<0.05 \&{ }^{*} \star * \mathrm{P}<0.001$ vs. sham group. \#\#P<0.01 vs. PD group after 3 weeks' post-surgery. (PD=lesion group, $L D=L D O P A 20 \mathrm{mg} / \mathrm{kg}$ treated group, BA0.5, BA5, BA10 $=$ Betulinic acid $10 \mathrm{mg} / \mathrm{kg}$ treated groups)

A
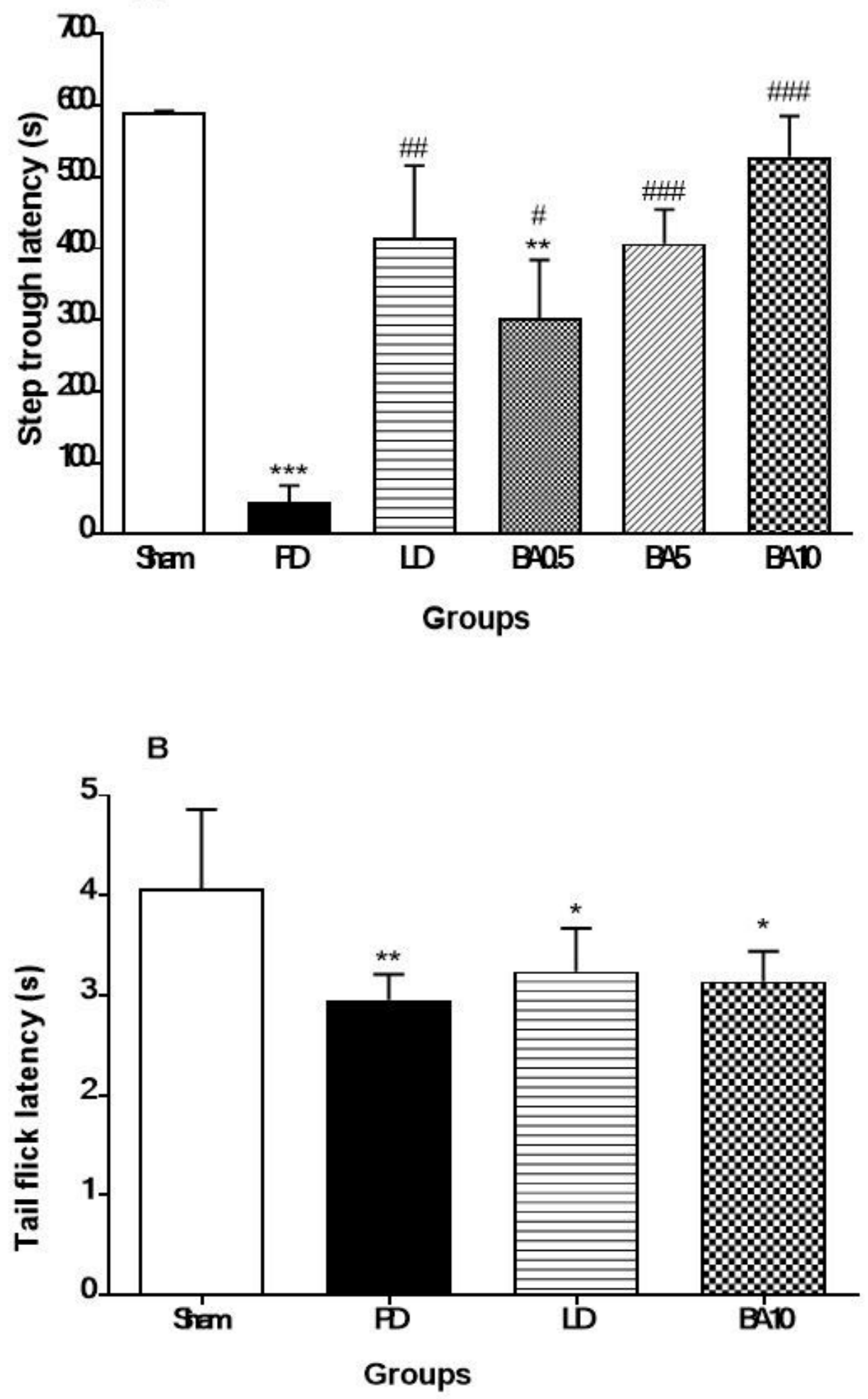

Figure 4

The effects of Betulinic acid and L-dopa on passive avoidance in Shuttle box (A), The effects of Betulinic acid and L-dopa on pain in Tail Flick (B), in PD rats. The results were expressed as mean \pm SEM $(n=8)$. 
Data analyzed by one-way ANOVA followed by Tukey's post hoc test for among multiple groups comparison. ${ }^{*} P<0.05 \&$ * ${ }^{*} P<0.01 \&{ }^{\star} * * P<0.001$ vs. sham group. $\# P<0.05 \& \# \# P<0.01 \& \# \# \# P<0.001$ vs. PD group after 3 weeks' post-surgery. (PD=lesion group, LD=LDOPA $20 \mathrm{mg} / \mathrm{kg}$ treated group, BA0.5, BA5, BA10 = Betulinic acid $0.5 \mathrm{mg} / \mathrm{kg}, 5 \mathrm{mg} / \mathrm{kg}, 10 \mathrm{mg} / \mathrm{kg}$ treated groups)
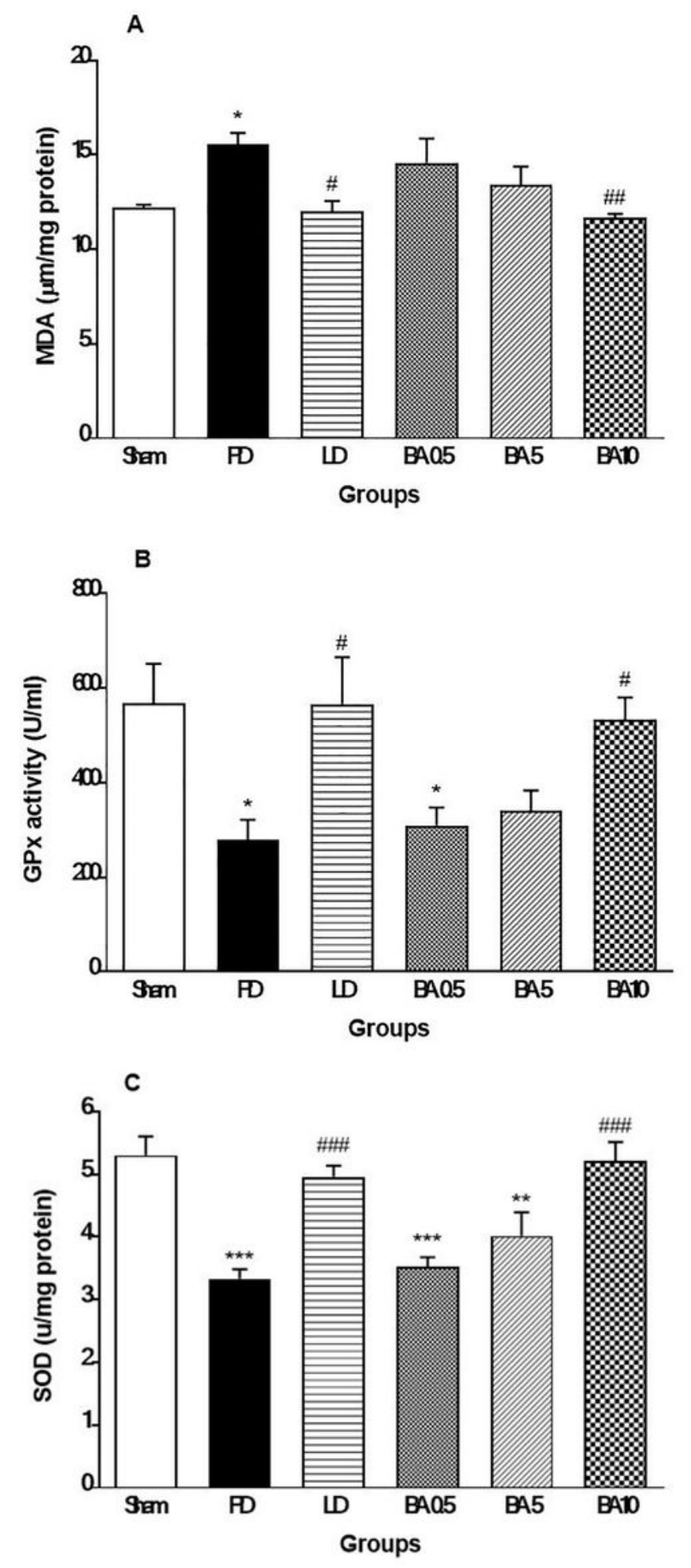

Figure 5 
The effects of Betulinic acid and L-dopa on the level of MDA (A), GPX (B) \& SOD (C). The results were expressed as mean \pm SEM $(n=8)$. Data analyzed by one-way ANOVA followed by Tukey's post hoc test for among multiple groups comparison. ${ }^{*} \mathrm{P}<0.05,{ }^{*} \mathrm{P}<0.01 \&$ \& ${ }^{\star \star *} \mathrm{P}<0.001$ vs. sham group. $\# \mathrm{P}<0.05, \# \# \mathrm{P}<0.01$ \& \#\#\#P<0.001 vs. PD group after 3 weeks' post-surgery. ( $P D=$ Lesioned group, $L D=L D O P A 20 \mathrm{mg} / \mathrm{kg}$ treated group, BA0.5, BA5, BA10 = Betulinic acid $0.5 \mathrm{mg} / \mathrm{kg}, 5 \mathrm{mg} / \mathrm{kg}, 10 \mathrm{mg} / \mathrm{kg}$ treated groups)

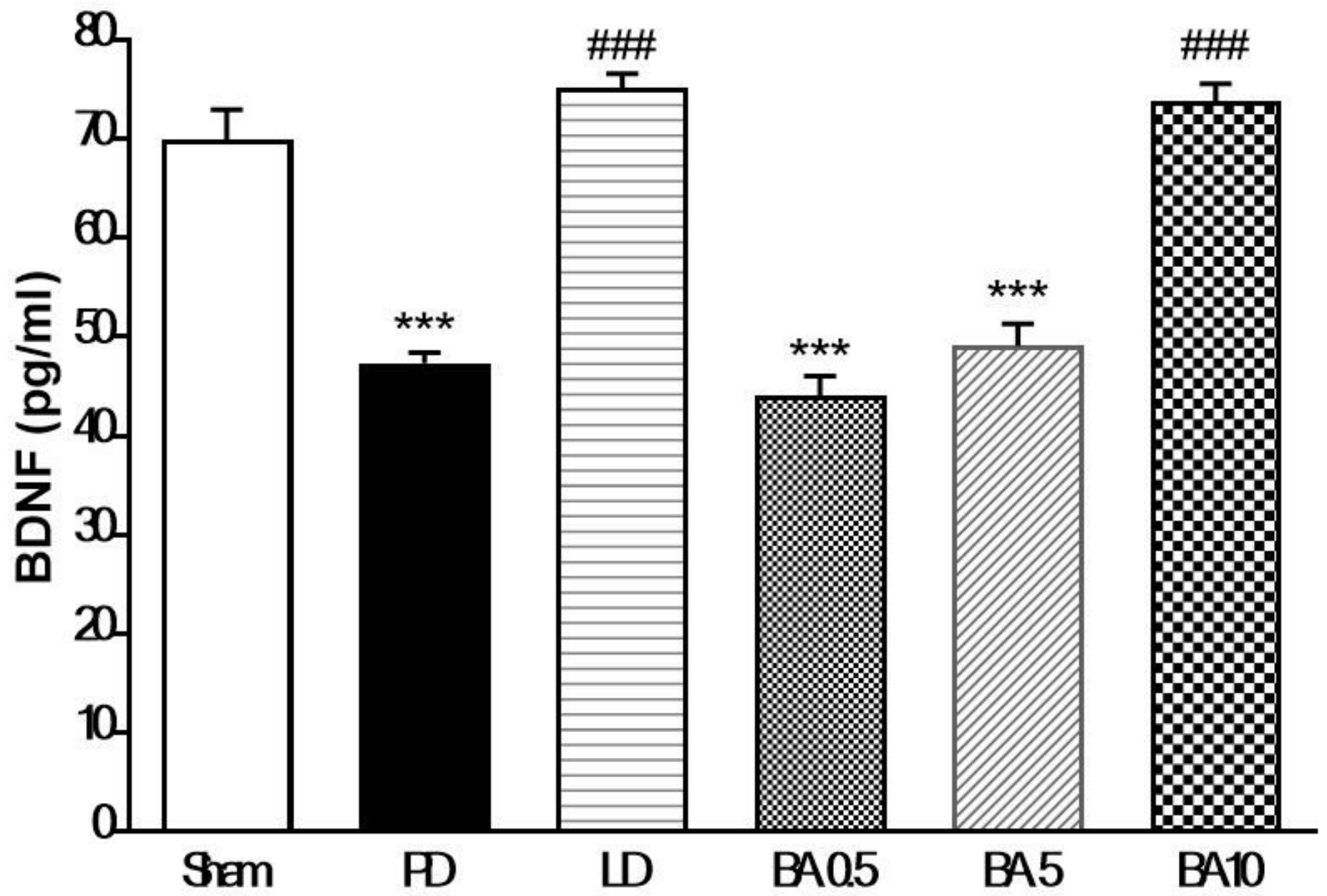

\section{Groups}

Figure 6

The effects of Betulinic acid and L-dopa on neurotrophic (BDNF) levels. The results were expressed as mean \pm SEM $(n=8)$. Data analyzed by one-way ANOVA followed by Tukey's post hoc test for among multiple groups comparison. ${ }^{* \star *} P<0.001$ vs. sham group. \#\#\#P<0.001 vs. PD group after 3 weeks' post-

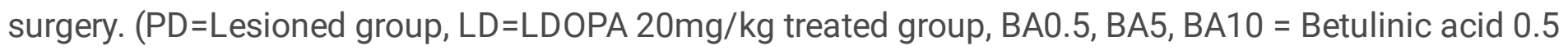
$\mathrm{mg} / \mathrm{kg}, 5 \mathrm{mg} / \mathrm{kg}, 10 \mathrm{mg} / \mathrm{kg}$ treated groups) 


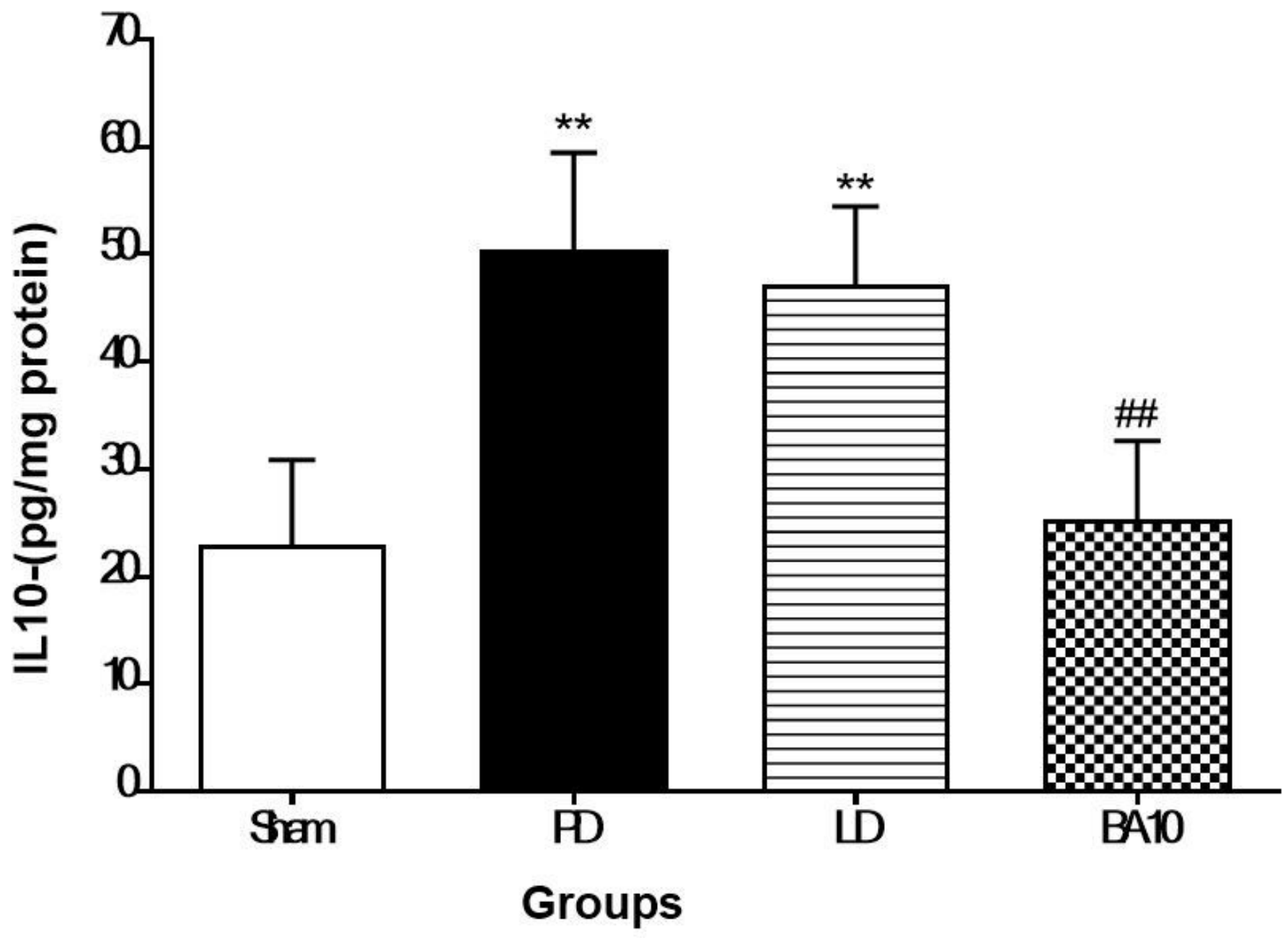

Figure 7

The effects of Betulinic acid and L-dopa on cytokine IL10 levels. The results were expressed as mean \pm SEM $(n=8)$. Data analyzed by one-way ANOVA followed by Tukey's post hoc test for among multiple groups comparison. ${ }^{\star} \times P<0.01$ vs. sham group. \#\#P<0. 01 vs. PD group after 3 weeks' post-surgery. (PD=Lesioned group, $\mathrm{LD}=\mathrm{LDOPA} 20 \mathrm{mg} / \mathrm{kg}$ treated group, BA10 = Betulinic acid, $10 \mathrm{mg} / \mathrm{kg}$ treated groups) 